\title{
Sensitivity of wild and domesticated Rhododendron chrysanthum to different light regime (UVA, UVB, and PAR)
}

\author{
J. LYU*, C. WANG*, D.Y. LIANG*, L. LIU*, L.K. PANDEY**, H.W. XU,,+, and X.F. ZHOU ${ }^{*},+$ \\ Jilin Provincial Key Laboratory of Plant Spectral Regions Science and Green Production, Jilin Normal University, \\ 136000 Siping, China* \\ Department of Plant Science, Faculty of Applied Sciences, MJP Rohilkhand University, 243006 Bareilly, India**
}

\begin{abstract}
Effects of UV radiation on photosynthetic capacity of wild and domesticated Rhododendron chrysanthum were compared by applying PAR (P), P + UVA (PA), and P + UVA + UVB (PAB) radiation for $3 \mathrm{~d}$, respectively. Results showed that photosynthetic activity of two $R$. chrysanthum types was not affected by UVA but inhibited by UVB, and the inhibitory effects of UVB were dose-dependent. Changes in nonphotochemical quenching suggest that the range of photosynthetic capacity is ranked as follows: $24-48 \mathrm{~h}$ of UVB dose $<$ wild type $<72 \mathrm{~h}$ of UVB dose $<$ domesticated type, indicating that the wild type initiated photoprotective function in response to UVB stress due to its lower photosynthetic capacity, while domesticated type did not due to its higher photosynthetic capacity. Taken all the given data together, the wild type was more sensitive to UV stress, but it showed more effective mechanisms of counteracting it.
\end{abstract}

Additional key words: alpine plant; photoinhibition; photoprotection; photosynthesis.

\section{Introduction}

Though accounting for only a small fraction of the total UV radiation, UVB $(280-315 \mathrm{~nm})$ has been traditionally considered as stress as it can potentially induce a number of deleterious effects in plants, including growth reduction, partial inhibition of photosynthesis, changes in plant biochemistry, oxidative damage, and disruption of the integrity and function of important macromolecules (DNA, proteins, and lipids) (Rastogi et al. 2010, Albert et al. 2011, Hideg et al. 2013, Widel et al. 2014).

Some studies found no effect of UVB on the net photosynthesis (Klem et al. 2012, Alonso et al. 2015) due to a short-term treatment. Some studies found low levels of UVB increased net photosynthesis (Yang and Yao 2008, Klem et al. 2015, Vidović et al. 2015, Guidi et al. 2016). However, the deleterious effects of UVB on photosynthesis have been observed mostly under high, unnatural doses of UVB (Dehariya et al. 2012).

Photon energy captured by a Chl $a$ molecule can either drive photosynthesis (photochemical quenching, $\mathrm{q}_{\mathrm{p}}$ ), be emitted as fluorescence, or be converted to heat (nonphotochemical quenching, $\mathrm{q}_{\mathrm{N}}$ and NPQ) (Schreiber 2004). Over the past 30 years, the measurement of the Chl $a$ fluorescence has proven to be a powerful method of assessing the properties of the photosynthetic apparatus (Schreiber 2004, Ralph and Gademann 2005). Light curves provide detailed information on the saturation characteristics of electron transport, as well as the overall photosynthetic performance of a plant. Derived cardinal points of a rapid light curve $\left(\alpha, \mathrm{E}_{\mathrm{k}}\right.$, and $\left.\mathrm{rETR}_{\max }\right)$ describe the photosynthetic capacity of a leaf. The relative ETR, rETR, is an approximation of the rate of electrons pumped through the photosynthetic chain (Beer et al. 2001). $\alpha$ reflects photosynthetic rate in light-limited region of light curve. The rise of the curve in the light-limiting region $(\alpha)$ is proportional to efficiency of light capture (effective quantum yield, Schreiber 2004). Minimum saturating irradiance, $\mathrm{E}_{\mathrm{k}}$, is related to quenching, where photochemical quenching dominates below $\mathrm{E}_{\mathrm{k}}$, while nonphotochemical quenching dominates the fluorescence quenching above $\mathrm{E}_{\mathrm{k}}$ (Henley 1993). $\mathrm{rETR}_{\max }$ is maximum relative electron transport rate. Under moderate irradiance, the capacity of the electron transport chain limits photosynthesis and the curve reaches a plateau, where maximum photosynthetic capacity occurs $\left(\mathrm{rETR}_{\max }\right)$ (Schreiber 2004). Photochemical quenching, $\mathrm{q}_{\mathrm{P}}$, namely the fluorescence quenching caused by photosynthesis, reflects the level of photosynthetic

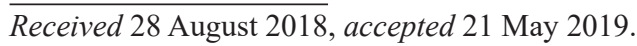

${ }^{+}$Corresponding author; e-mail: zhouxiaofu@jlnu.edu.cn (X.F. Zhou), xuhongwei@jlnu.edu.cn (H.W. Xu)

Abbreviations: $\mathrm{D}$ - domesticated type of Rhododendron chrysanthum; $\mathrm{E}_{\mathrm{k}}-$ minimum saturating irradiance; $\mathrm{F}_{\mathrm{v}} / \mathrm{F}_{\mathrm{m}}-$ maximum quantum yield of PSII; NPQ - nonphotochemical quenching; P - PAR; PA - PAR + UVA; PAB - PAR + UVA + UVB; rETR - relative electron transport rate; $\mathrm{rETR}_{\max }$ - maximum relative electron transport rate; $\mathrm{q}_{\mathrm{P}}$ - photochemical quenching; $\mathrm{W}$ - wild type of $R$. chrysanthum; $\alpha$ - photosynthetic rate in light-limited region of light curve; $\Phi_{\mathrm{PSII}}-$ effective quantum yield of PSII.

Acknowledgment: This study was supported by the National Natural Science Foundation of China (31070224) and the Jilin Provincial Department of Science and Technology (20130206059NY). 
activity. Nonphotochemical quenching, NPQ, reflects the ability of plants to dissipate excess light energy as heat, reflecting the photoprotective ability of plant. Maximum quantum yield of PSII, $F_{v} / F_{m}$, reflects the potential maximum photosynthetic capacity of plants (photosynthetic efficiency). Effective quantum yield of PSII, $\Phi_{\text {PSII }}$, is actual photosynthetic capacity or actual photosynthetic efficiency at any light state.

In previous laboratory investigations, inhibition of $\mathrm{F}_{\mathrm{v}} / \mathrm{F}_{\mathrm{m}}$ was observed in oat (Avena sativa $\mathrm{L}$.) due to UVB radiation, suggesting the photoinhibition changes in the PSII of the leaves (Skórska 1999). During a 10-d study of winter wheat (Triticum aestivum L.) treated by enhanced UVB radiation, decreased photosynthetic rate $\left(P_{\mathrm{N}}\right)$ and $\mathrm{F}_{\mathrm{v}} / \mathrm{F}_{\mathrm{m}}$ were observed (Yang et al. 2007). The ratio of $\mathrm{F}_{\mathrm{v}} / \mathrm{F}_{\mathrm{m}}$ was significantly reduced by UVB in two grapevine (Vitis vinifera L.) cultivars (Schoedl et al. 2013). Similar results can be seen from the experiments outdoors under ambient UV. For example, Reddy et al. (2004) found that UVB exposure of cotton (Gossypium hirsutum L.) led to reduced $\mathrm{F}_{\mathrm{v}} / \mathrm{F}_{\mathrm{m}}$, in addition to reductions in net photosynthesis. Fluorescence measurements indicated enhanced $F_{v} / F_{m}$ ratio and reduction capacity after exclusion of solar UV (Dehariya et al. 2012).

Response of plants to UVB radiation is turned out to be the result of a comprehensive balance of injury, remediation, and acclimation (Quesada et al. 1995, Jansen et al. 1998). While there is still little information regarding the mechanistic changes driving UVB-mediated increases in photosynthesis, recent work on the woody shrub Pimelea ligustrina demonstrated that UVA radiation increased in situ photosynthetic rates in P. ligustrina by $12 \%$, a response which was attributed to the excitation of Chl $a$ by UVA directly (Turnbull et al. 2013). Some studies found UVA enhanced net photosynthesis (Yang and Yao 2008, Bernal et al. 2015, Štroch et al. 2015) and increased the quantum yield efficiency of plants (Kolb et al. 2001). Some studies found that UVA did not affect the quantum yield efficiency of most vegetables and monocots (Guruprasad et al. 2007, Yang and Yao 2008, Bernal et al. 2015, Štroch et al. 2015). However, other studies found that UVA radiation had a detrimental effect on photosynthesis (Turcsányi and Vass 2000) and reduced the quantum yield efficiency of plants (Tohidi-Moghadam et al. 2012, Joshi et al. 2013).

Responses of photosynthesis to UVB radiation can be regulated by other environmental factors, such as climatic factors, PAR, nutrient status, drought, $\mathrm{CO}_{2}$, and particularly growth temperature (Murali and Teramura 1987, Sullivan and Teramura 1990, Visser et al. 1997, Yang et al. 2007). Vidović et al. (2015) reported that the effects on white-edged Swedish ivy might be influenced by the UVB/PAR ratio during the experiment at low PAR levels, the quantum yield efficiency increased but was not affected at higher PAR. The net photosynthetic rate of cotton (Gossypium hirsutum L.) plants treated by $0.16 \mathrm{~W}$ $\mathrm{m}^{-2} \mathrm{UVB}$ radiation did not change at $24 / 16^{\circ} \mathrm{C}$ (day/night temperature) but decreased at $30 / 22$ and $36 / 28^{\circ} \mathrm{C}$ (Reddy et al. 2004). However, UVB-induced photoinhibition of cucumber (Cucumis sativus L.) cotyledons was relieved by increasing temperature from 20 to $25^{\circ} \mathrm{C}$ (Takeuchi et al. 1993). In a 10-d study of winter wheat (Triticum aestivum L.) treated by enhanced UVB radiation, low temperature intensified UVB-induced photoinhibition, which was indicated by decreased $P_{\mathrm{N}}$ and $\mathrm{F}_{\mathrm{v}} / \mathrm{F}_{\mathrm{m}}$ and by weakened antioxidant system (Yang et al. 2007). Future studies will also need to consider the potential interactive effects between UVB and UVA and other environmental factors with particular interest in growth temperature (Yang et al. 2007).

Rhododendron chrysanthum only grows at altitudes between 1,300 and 2,650 $\mathrm{m}$ at the Changbai Mountain in the southeastern part of Jilin Province in China. At the top of the mountain, the annual average temperature is $-7.3^{\circ} \mathrm{C}$. The harsh climate and poor soil at the top of the Changbai Mountain are serious challenge for plants. The long adaptive evolution process of $R$. chrysanthum allows it to resist cold temperatures, drought, strong UV radiation, and other abiotic stresses (Zhou et al. 2017). R. chrysanthum plants grown on top of the mountain (wild type) and in plain (domesticated for 10 years) were chosen for testing the adaptability of plants to UV radiation.

Physiological characteristics of two $R$. chrysanthum types were reported in our previous study (Zhou et al. 2017). A total of 1,395 proteins were identified, among which 137 proteins were upregulated in the wild $R$. chrysanthum. The activities of superoxide dismutase (SOD), catalase (CAT), ascorbate peroxidases (APXs), and glutathione peroxidase (GPX) were significantly higher and the expression of APXs and GPX also increased in the wild R. chrysanthum. Moreover, the interaction network analysis of these enzymes also revealed that the antioxidant enzymes play important roles in the stress resistance in plants (Zhou et al. 2017). Understanding the effect of UV on alpine plants are limited, although pioneering work of Albert et al. (2005) demonstrated that leaves of Salix arctica, an alpine plant living in 2,000-2,800 $\mathrm{m}$ a.s.1., were less stressed under UVB exclusion as compared to leaves exposed to high PAR and high UVB. These reports suggest the necessity for further study on possible defense mechanisms of alpine plants irradiated with UV.

In the present study, we used the $R$. chrysanthum as a material to study the adaptability of photosynthesis capacity of alpine plants to UVB and UVA radiation. We also tried to investigate whether the strong solar UV radiation on the top of Changbai Mountain affects the photosynthesis of plants and if so, what is the adaptability of typical alpine plants to cope up with the strong UV radiation for long-term living in harsh environments on the plateau.

\section{Materials and methods}

Plant material: Rhododendron chrysanthum was collected at altitudes between $1,300 \mathrm{~m}$ and $2,650 \mathrm{~m}$ on the Changbai Mountain. After transport to the laboratory, the plants were maintained in an artificial climate room under a simulated alpine environment and cultured in the chamber, respectively. Wild $R$. chrysanthum plants (W type) were grown in an artificial climate room at $18^{\circ} \mathrm{C}(14-\mathrm{h}$ light $) / 16^{\circ} \mathrm{C}(10-\mathrm{h}$ dark $)$ under white 
fluorescent light at $50 \mu \mathrm{mol}($ photon $) \mathrm{m}^{-2} \mathrm{~s}^{-1}$. Domesticated $R$. chrysanthum plants ( $\mathrm{D}$ type) were grown in the chamber at $24^{\circ} \mathrm{C}$ under white fluorescent light at $50 \mu \mathrm{mol}$ (photon) $\mathrm{m}^{-2} \mathrm{~s}^{-1}$.

Experimental design: To investigate whether there is a difference in the photosynthetic capacity between $\mathrm{W}$ type and D type under UV radiation, the experiments were performed by exposing 8-month-old seedlings of two R. chrysanthum types to photosynthetically active radiation (PAR), PAR + UVA (PA), and PAR + UVA + UVB (PAB) radiation for $3 \mathrm{~d}$. Plants from each treatment were withdrawn at 24-h intervals in triplicates and tested for their photosynthetic capacity.

PAR and UV radiation exposure: The plants of two R. chrysanthum types (W and D) were exposed to artificial radiation of UVB (280-315 nm), UVA (315-400 nm), and PAR $(400-700 \mathrm{~nm})$ in replicates $(n=3)$. To obtain the three desired radiation regimes, long-pass filters of different transmittance characteristics were used. A 400-nm long-pass filter (Edmund, Filter Long 2IN SQ, NJ, USA) was placed over the culture bottle in the PAR-only treatment. For the PAR + UV treatments 320- or 295-nm long-pass filters (Edmund, Filter Long 2IN SQ, NJ, USA) were placed over the culture bottles to achieve the PA or $\mathrm{PAB}$ regime, respectively. Visible (PAR) light was supplied by warm white fluorescent light lamp (Philips, $T 5 \times 14 \mathrm{~W}$, The Netherlands). UVA radiation was provided by UVA fluorescence tubes (Philips, UVA-340 TL 20W/05, The Netherlands), and UVB fluorescence tubes (Philips, Ultraviolet-B TL 20W/01 RS, The Netherlands) were used as a source of artificial UVB radiation. Based on the transmittance function of the long pass filters, the irradiances effectively received by the samples were: $2.3 \mathrm{~W} \mathrm{~m} \mathrm{~m}^{-2} \mathrm{UVB}, 1.5 \mathrm{~W} \mathrm{~m}^{-2} \mathrm{UVA}$, and PAR of 50 $\mu \mathrm{mol}\left(\right.$ photon) $\mathrm{m}^{-2} \mathrm{~s}^{-1}$.

Chl fluorescence measurements: For a 3-d study of UV exposure on $R$. chrysanthum, the 8-month-old seedlings were grown under three radiation conditions (P, PA, and PAB) for $8 \mathrm{~h}$, followed by the illumination under white light for the remaining $16 \mathrm{~h}$ daily. During the experimental period, none of the plants experienced any water or nutrient stress. Induction curves and light curves were obtained by using an imaging pulse amplitude modulation fluorometer (IMAGING PAM M-series, Walz, Effeltrich, Germany). Dark period of the samples was set at least $15 \mathrm{~min}$ before $\mathrm{Chl}$ fluorescence measurements. From the light curves we obtained the parameters $\alpha, \mathrm{rETR}_{\max }$, and $\mathrm{E}_{\mathrm{k}}$. Then, we compared the exact photosynthetic performance by analyzing these parameters.

Statistical analysis: One- or two-way analyses of variance (ANOVA) were performed using SPSS 16.0 (NY, USA) to test the single and interactive effects of different light sources used, i.e., PAR, UVA, UVB, and their different sets of combination. When the ANOVA results showed a significant difference, the least significant difference (LSD) as a post-hoc test at $P<0.05$ was calculated to compare the mean values of the various treatment groups. The figures were drawn with Sigmaplot 12.5 (Systa Software Inc., Chicago, IL, USA).

\section{Results and discussion}

Effect of UVA on $F_{v} / F_{m}, \Phi_{P_{I I I}}, \mathbf{r E T R}_{\max }, \alpha$, and $\mathbf{E}_{\mathrm{k}}$ : $\mathrm{F}_{\mathrm{v}} / \mathrm{F}_{\mathrm{m}}$ of wild $R$. chrysanthum $\left(\mathrm{W}-\mathrm{F}_{\mathrm{v}} / \mathrm{F}_{\mathrm{m}}\right)$ depends on the dose of UVA radiation. For example, $\mathrm{W}-\mathrm{F}_{\mathrm{v}} / \mathrm{F}_{\mathrm{m}}$ was significantly inhibited by UVA at $72 \mathrm{~h}$, since $\mathrm{P}$ treatment displayed a significant decrease in $\mathrm{W}-\mathrm{F}_{\mathrm{v}} / \mathrm{F}_{\mathrm{m}}$ in comparison with PA treatment only after $72 \mathrm{~h}$ (Fig. 1A). This is further demonstrated by the fact that $\mathrm{W}-\mathrm{F}_{\mathrm{v}} / \mathrm{F}_{\mathrm{m}}$ at $72 \mathrm{~h}$ was significantly lower than that at 24 or $48 \mathrm{~h}$ under PA conditions (Fig. 1A). However, UVA did not affect $\Phi_{\text {PSII, }}$ $\mathrm{rETR}_{\max }, \alpha$, and $\mathrm{E}_{\mathrm{k}}$ of wild $R$. chrysanthum (Fig. $1 B-D$ ). For example, no significant difference in $\mathrm{W}_{-} \mathrm{rETR}_{\max }$, $\mathrm{W}-\alpha$, and $\mathrm{W}-\mathrm{E}_{\mathrm{k}}$ was found between $\mathrm{P}$ and $\mathrm{PA}$ treatment (Fig. $1 C-E$ ). Although W- $\Phi_{\text {PSII }}$ significantly increased by UVA radiation at $48 \mathrm{~h}$, it was recovered at $72 \mathrm{~h}$ (Fig. $1 B$ ). $\mathrm{W}_{-} \mathrm{rETR}_{\max }$ significantly increased by UVA radiation at $24 \mathrm{~h}$, whereas, it was recovered after $48 \mathrm{~h}$ of radiation (Fig. 1C). $\mathrm{W}-\alpha$ significantly decreased by UVA radiation at $24 \mathrm{~h}$, but it significantly increased at $48 \mathrm{~h}$ and recovered until $72 \mathrm{~h}$ (Fig. 1D). A similar pattern can be seen for $\mathrm{W}-\mathrm{E}_{\mathrm{k}}$ (Fig. 1E).

In domesticated $R$. chrysanthum, UVA did not affect $\mathrm{F}_{\mathrm{v}} / \mathrm{F}_{\mathrm{m}}, \Phi_{\mathrm{PSII}}, \mathrm{rETR}_{\max }$, and $\mathrm{E}_{\mathrm{k}}$ regardless of exposure time (Fig. $1 F, G, H, J)$. No significant differences in $\mathrm{D}-\mathrm{F}_{\mathrm{v}} / \mathrm{F}_{\mathrm{m}}$, $\mathrm{D}-\Phi_{\mathrm{PSII}}, \mathrm{D}-\mathrm{rETR} \mathrm{R}_{\max }$, and $\mathrm{D}-\mathrm{E}_{\mathrm{k}}$ were found between $\mathrm{P}$ and PA treatment regardless of exposure time (Fig. $1 F, G, H, J$ ). On the contrary, D- $\alpha$ depends on the dose of UVA radiation. For instance, D- $\alpha$ was significantly inhibited by UVA after $48 \mathrm{~h}$ of radiation, since $\mathrm{P}$ treatment displayed a significant decrease in $\mathrm{D}-\alpha$ in comparison with PA treatment after $48 \mathrm{~h}$ of radiation (Fig. $1 I$ ). As a result, wild $R$. chrysanthum was more susceptible to UVA than domesticated $R$. chrysanthum in terms of $\mathrm{F}_{\mathrm{v}} / \mathrm{F}_{\mathrm{m}}$ and $\alpha$. For example, $\mathrm{W}-\mathrm{F}_{\mathrm{v}} / \mathrm{F}_{\mathrm{m}}$ was significantly reduced by UVA at $72 \mathrm{~h}$, whereas, no significant difference in $D-F_{v} / F_{m}$ was found between $P$ treatment and PA treatment regardless of exposure time (Fig. $1 A, F$ ). In addition, $\mathrm{W}-\alpha$ was significantly inhibited by UVA radiation at the first $24 \mathrm{~h}$, but it significantly increased at $48 \mathrm{~h}$ and recovered until $72 \mathrm{~h}$ (Fig. 1D). However, D- $\alpha$ was significantly inhibited by UVA since $48 \mathrm{~h}$ post radiation and was not recovered until $72 \mathrm{~h}$ (Fig. 1I). In addition, $\Phi_{\text {PSII }}, \mathrm{rETR}_{\max }$, and $\mathrm{E}_{\mathrm{k}}$ of two $R$. chrysanthum types were not susceptible to UVA radiation.

Effect of UVA on $q_{P}$ and NPQ: The NPQ of the alpine Rhododendron was regulated by the light intensity of PAR. When the light intensity was less than $100 \mu \mathrm{mol}$ (photon) $\mathrm{m}^{-2} \mathrm{~s}^{-1}$, NPQ of two Rhododendron types increased rapidly. After that, the NPQ of the two types of Rhododendron tended to be stable with the increase of light intensity (Fig. 2).

Both NPQ and q of two Rhododendron types were not affected by UVA. For example, there was no significant difference in NPQ between the PA and P for both types of Rhododendron after UV-irradiation for 24-72h(Fig. $2 B-D$ ). 


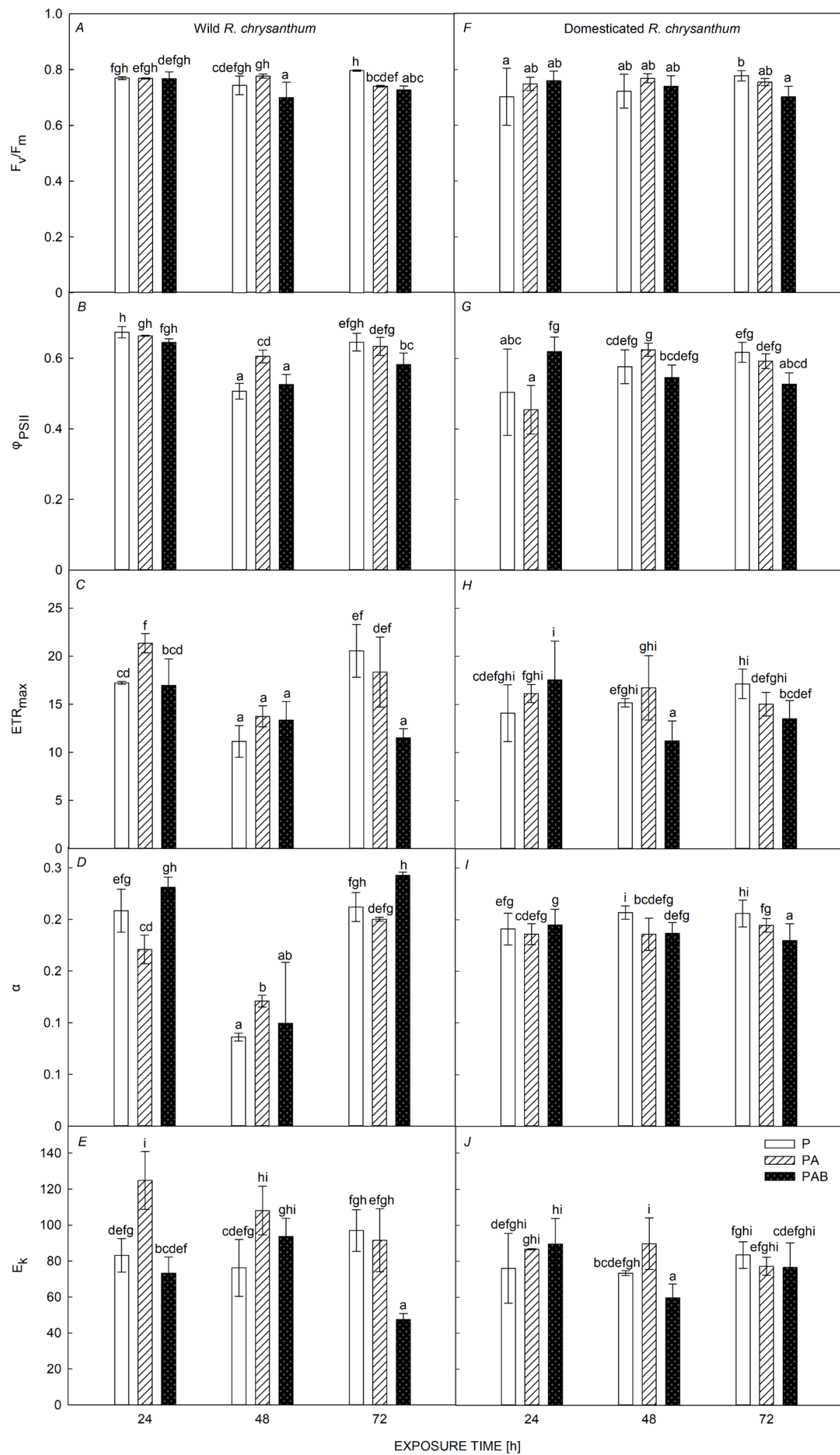

Fig. 1. Maximum quantum yield of $\operatorname{PSII}\left(\mathrm{F}_{\mathrm{v}} / \mathrm{F}_{\mathrm{m}}\right)$, effective quantum yield of PSII $\left(\Phi_{\text {PSII }}\right)$, maximum relative electron transport rate $\left(\mathrm{rETR}_{\max }\right)$, photosynthetic rate in light-limited region of light curve $(\alpha)$, and minimum saturating irradiance $\left(E_{k}\right)$ of wild and domesticated Rhododendron chrysanthum exposed to PAR (P), PAR + UVA (PA) or PAR + UVA + UVB (PAB). Values are means $\pm \operatorname{SE}(n=3)$. Different lowercase letters indicate statistically significant difference $(P<0.05)$ in the same figure block.

Similar pattern can be seen for $\mathrm{q}_{\mathrm{P}}$ (Fig. $3 B-D$ ). This can be explained by the fact that the intensity of UVA applied in this study did not exceed the photosynthetic capacity of both Rhododendron types (Fig. 2). This can be further proved by its habitat environment in nature; the light intensity of UVA applied in this experiment was lower than that in the alpine environment.

Effect of UVB on $\mathbf{F}_{\mathrm{v}} / \mathbf{F}_{\mathrm{m}}, \boldsymbol{\Phi}_{\mathrm{PSI}}, \mathbf{r E T R} \mathbf{R}_{\max }, \boldsymbol{\alpha}$, and $\mathbf{E}_{\mathrm{k}}: \mathrm{F}_{\mathrm{v}} / \mathrm{F}_{\mathrm{m}}$, $\Phi_{\text {PSII }}$, rETR $_{\max }, \alpha$, and $\mathrm{E}_{\mathrm{k}}$ of wild $R$. chrysanthum depended 

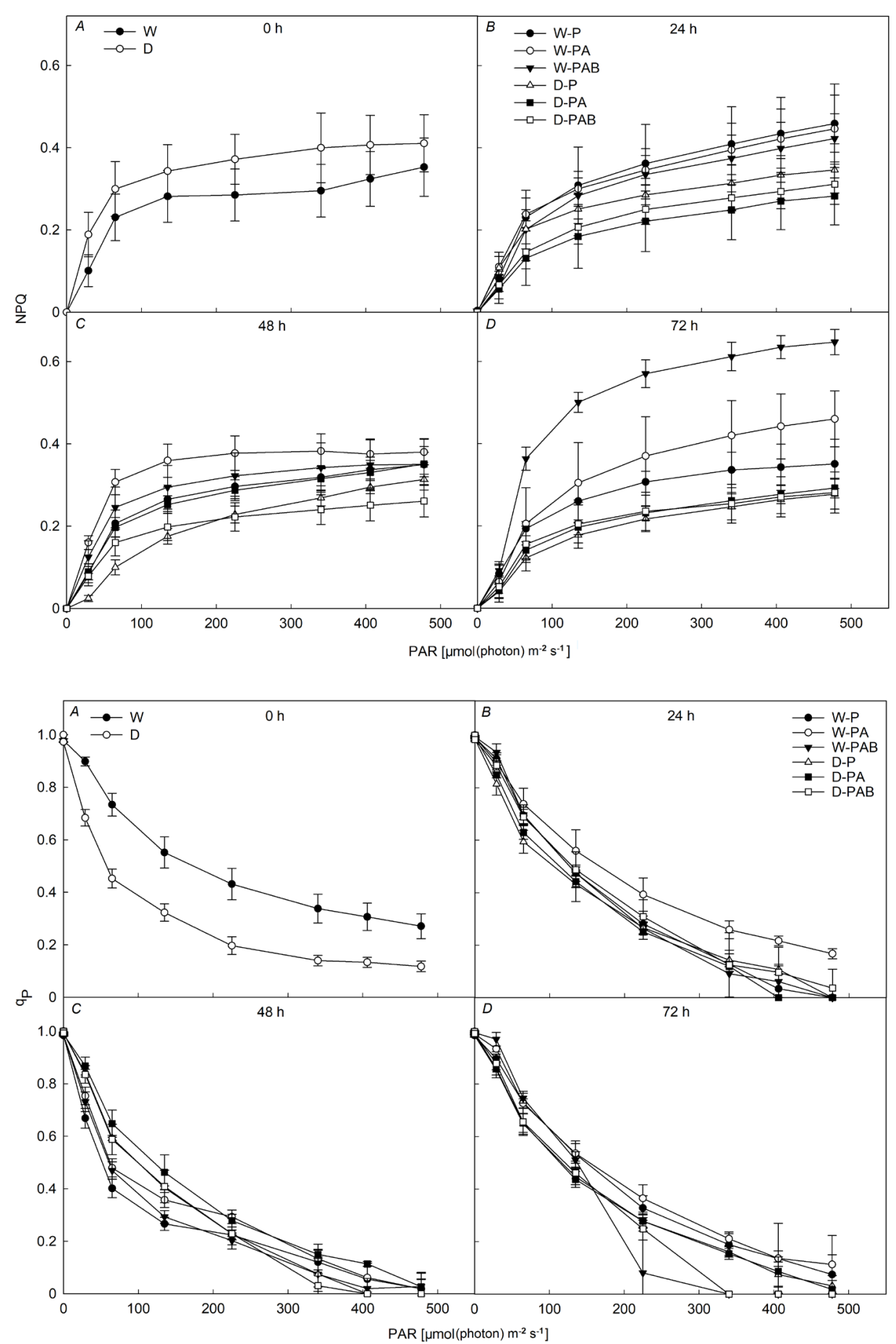

Fig. 2. Mean nonphotochemical quenching (NPQ) as a function of PAR, obtained from wild (W) and domesticated (D) Rhododendron chrysanthum leaf exposed to PAR $(\mathrm{P}), \mathrm{PAR}+$ UVA (PA) or PAR + $\mathrm{UVA}+\mathrm{UVB}(\mathrm{PAB})$ for $0 \mathrm{~h}(A)$, $24 \mathrm{~h}(B), 48 \mathrm{~h}(C)$, and $72 \mathrm{~h}(D)$. Values are means \pm confidence $(n=3)$.

Fig. 3. Mean photochemical quenching $\left(\mathrm{q}_{\mathrm{P}}\right)$ as a function of PAR, obtained from wild (W) and domesticated (D) Rhododendron chrysanthum leaf exposed to PAR (P), PAR + UVA (PA) or PAR + $\mathrm{UVA}+\mathrm{UVB}(\mathrm{PAB})$ for $0 \mathrm{~h}(A)$, $24 \mathrm{~h}(B), 48 \mathrm{~h}(C)$, and $72 \mathrm{~h}(D)$. Values are means \pm confidence $(n=3)$.

on the duration of UVB radiation. For example, $\mathrm{W}-\mathrm{F}_{\mathrm{v}} / \mathrm{F}_{\mathrm{m}}$ significantly decreased by UVB only after $48 \mathrm{~h}$ since PA treatment displayed a significant decrease in $\mathrm{W}-\mathrm{F}_{\mathrm{v}} / \mathrm{F}_{\mathrm{m}}$ in comparison with PAB treatment, and it was not affected at either $72 \mathrm{~h}$ or the first $24 \mathrm{~h}$ (Fig. $1 A$ ). W- $\Phi_{\text {PSII }}$ was not affected by UVB in the first $24 \mathrm{~h}$. However, it was significantly inhibited by UVB during the following $2 \mathrm{~d}$, i.e., 48 and 72 h. For example, there was no significant difference in $\mathrm{W}-\Phi_{\mathrm{PSII}}$ between PA treatment and PAB treatment at $24 \mathrm{~h}$, but the former displayed a significant decrease in comparison to the latter after 48-h radiation
(Fig. 1B). This is further demonstrated by the fact that $\mathrm{W}_{-} \mathrm{HTR}_{\max }$ and $\mathrm{W}-\mathrm{E}_{\mathrm{k}}$ irradiated by PAB were significantly lower than that irradiated by PA after both 24 and $72 \mathrm{~h}$ (Fig. 1C,E). The opposite trend can be seen for $\mathrm{W}-\alpha$ (Fig. $1 D)$. This is in accordance with the recent review (Neugart and Schreiner 2018): the effects of UVB and UVA depend on the genotype, the developmental stage of the plant, and the intensity and duration of the UVB or UVA treatment.

For domesticated $R$. chrysanthum, UVB did not affect $\mathrm{F}_{\mathrm{v}} / \mathrm{F}_{\mathrm{m}}$ regardless of the duration of UVB radiation (Fig. $1 B$ ). However, $\Phi_{\text {PSII }}, \mathrm{rETR}_{\max }, \alpha$, and $\mathrm{E}_{\mathrm{k}}$ of domesti- 
cated $R$. chrysanthum depended on the duration of UVB radiation. For example, D- $\Phi_{\mathrm{PSII}}$ was significantly affected only during the first $24 \mathrm{~h}$ (Fig. $1 G$ ). D-rETR max $_{\text {ax }}$ and D-E $\mathrm{E}_{\mathrm{k}}$ significantly decreased only at $48 \mathrm{~h}$ since PA treatment displayed a significant decrease in both D-rETR $_{\max }$ and $\mathrm{D}-\mathrm{E}_{\mathrm{k}}$ in comparison to the $\mathrm{PAB}$ treatment only after $48 \mathrm{~h}($ Fig. $1 H, J)$. Similarly, D- $\alpha$ was significantly inhibited by UVB only after $72 \mathrm{~h}$ since PA treatment displayed a significant decrease in $\mathrm{D}-\alpha$ in comparison to the PAB treatment only after $72 \mathrm{~h}$ (Fig. 1I).

Therefore, wild $R$. chrysanthum was more susceptible to UVB radiation than the domesticated type in terms of $\mathrm{F}_{\mathrm{v}} / \mathrm{F}_{\mathrm{m}}, \Phi_{\mathrm{PSII}}, \mathrm{rETR}_{\max }, \alpha$, and $\mathrm{E}_{\mathrm{k}}$. For example, UVB radiation showed significantly inhibiting effects on $\mathrm{W}-\mathrm{F}_{\mathrm{v}} / \mathrm{F}_{\mathrm{m}}$ at $48 \mathrm{~h}$, but not on $\mathrm{D}-\mathrm{F}_{\mathrm{v}} / \mathrm{F}_{\mathrm{m}}$ during the whole $3-\mathrm{d}$ radiation period (Fig. 1A,B). This is further demonstrated by the fact that $\Phi_{\text {PSII }}, \mathrm{rETR}_{\max }, \alpha$, and $\mathrm{E}_{\mathrm{k}}$ of wild $R$. chrysanthum was more frequently affected by UVB than that of domesticated R. chrysanthum (Fig. $1 B-E, G-J$ ).

Wild $R$. chrysanthum was more susceptible to UVA radiation than the domesticated $R$. chrysanthum in terms of $\mathrm{F}_{\mathrm{v}} / \mathrm{F}_{\mathrm{m}}$ and $\alpha$. Furthermore, wild $R$. chrysanthum was more susceptible to UVB radiation than domesticated R. chrysanthum in terms of $\mathrm{F}_{\mathrm{v}} / \mathrm{F}_{\mathrm{m}}, \Phi_{\mathrm{PSII}}, \mathrm{rETR}_{\max }, \alpha$, and $\mathrm{E}_{\mathrm{k}}$. This is further demonstrated by the fact that the time for the inhibition of $\mathrm{rETR}_{\max }$ caused by UVB in W type was $24 \mathrm{~h}$ less than that in D type.

In a recently reported experiment using grapevine (Vitis vinifera L. cv. Chardonnay), Majer and Hideg (2012) showed a similar effect of UVB radiation on photochemical yields as we observed in wild Rhododendron, namely the decrease in $\mathrm{F}_{\mathrm{v}} / \mathrm{F}_{\mathrm{m}}$ and $\Phi_{\mathrm{PSII}}$. The stimulated photoprotective mechanisms and reduced photosynthetic activities of the wild type in our study may contribute to limitation of photosynthesis observed by Majer and Hideg (2012). A decrease in $\mathrm{F}_{\mathrm{v}} / \mathrm{F}_{\mathrm{m}}$, ETR, and also photosynthesis reflects the loss of PSII activity, usually (but not always) following the degradation of D1 and D2 proteins induced by UVB. The proteins D1 and D2 of PSII RC play a great role in the sensitivity of PSII to UVB radiation; their degradation occurred at the UVB intensity of $0.53 \mathrm{~W} \mathrm{~m}^{-2}$ (Jansen et al. 1996). The key effect is the damage of PSII Mn-containing cluster (Melis et al. 1992, Vass et al. 1996, Tyystjarvi 2008, Kreslavski et al. 2009, Wei et al. 2011, Hou and Hou 2013). It is just this damage that promotes destruction of D1 protein (Kosobryukhov et al. 2015). In our experiment, a much higher intensity of UVB (8-h exposure to $2.3 \mathrm{~W} \mathrm{~m}^{-2} \mathrm{UVB}$ ) was applied to two $R$. chrysanthum types, causing a decrease in $\mathrm{F}_{\mathrm{v}} / \mathrm{F}_{\mathrm{m}}$ and $\mathrm{rETR}_{\max }$ in both of them after 48-h exposure, however, the decrease disappeared in the domesticated type after 72-h exposure (Table 1). This may suggest that degradation of proteins D1 and D2 occured in the wild types since $48 \mathrm{~h}$, but not in the domesticated type. Our ongoing research is characterizing the related proteins in two $R$. chrysanthum types, thereby to help understand the defense mechanism of the plant against UV radiation. This will be demonstrated in our future proteomic study.

Effect of UVB on $\mathbf{q}_{\mathbf{P}}$ and NPQ: NPQ in the wild type was affected by the dose of UVB more than that in the domesticated type. For example, after exposition of the wild type to UVB radiation for $24-48 \mathrm{~h}$, there was no significant change in NPQ (Fig. $2 B, C$ ), but it significantly increased after $72 \mathrm{~h}$ (Fig. 2D). However, there was no significant change in NPQ of the domesticated type during the whole period ( $24-72 \mathrm{~h}$ ) of UVB radiation (Fig. $2 B-D$ ). This suggests that the range of photosynthetic capacity is ranked as follows: $24-48 \mathrm{~h}$ of UVB dose $<$ wild type $<72 \mathrm{~h}$ of UVB dose $<$ domesticated type. These results demonstrate that, compared to the domesticated type, the wild type showed higher photoprotective function in response to UVB, which was due to its lower photosynthetic capacity. This is further demonstrated by the fact that in the absence of UVB, a photoprotective function, indicated as NPQ, of the wild type was slightly lower than that of

Table 1. Changes in photosynthetic capacity of wild (W) and domesticated (D) Rhododendron chrysanthum under UV radiation. $\mathrm{E}_{\mathrm{k}}$ - minimum saturating irradiance; $\mathrm{F}_{\mathrm{v}} / \mathrm{F}_{\mathrm{m}}$ - maximum quantum yield of PSII; NPQ - nonphotochemical quenching; $\mathrm{q}_{\mathrm{P}}$ - photochemical quenching; $\mathrm{rETR}_{\max }$ - maximum relative electron transport rate; $\alpha$ - photosynthetic rate in light-limited region of light curve; $\Phi_{\text {PSII }}$ - effective quantum yield of PSII. Green color indicates increase, red color indicates decrease, gray color indicates no change.

\begin{tabular}{|c|c|c|c|c|c|c|c|c|c|}
\hline Radiation & Rhododendron & Exposure time $[\mathrm{h}]$ & $\mathrm{F}_{\mathrm{v}} / \mathrm{F}_{\mathrm{m}}$ & $\Phi_{\mathrm{PSII}}$ & $\mathrm{rETR}_{\max }$ & Ek & $\alpha$ & NPQ & $\mathrm{q}_{\mathrm{P}}$ \\
\hline \multirow[t]{6}{*}{ UVA } & \multirow[t]{3}{*}{ W } & 24 & - & - & $\uparrow$ & $\uparrow$ & $\downarrow$ & - & - \\
\hline & & 48 & - & $\uparrow$ & - & $\uparrow$ & $\uparrow$ & - & - \\
\hline & & 72 & $\downarrow$ & - & - & - & - & - & - \\
\hline & \multirow[t]{3}{*}{$\mathrm{D}$} & 24 & - & - & - & - & - & - & - \\
\hline & & 48 & - & - & - & $\uparrow$ & - & - & - \\
\hline & & 72 & - & - & - & - & $\downarrow$ & - & - \\
\hline \multirow[t]{6}{*}{ UVB } & \multirow[t]{3}{*}{ W } & 24 & - & - & $\downarrow$ & $\downarrow$ & $\uparrow$ & - & - \\
\hline & & 48 & $\downarrow$ & $\downarrow$ & - & - & - & - & - \\
\hline & & 72 & - & $\downarrow$ & $\downarrow$ & $\downarrow$ & $\uparrow$ & $\uparrow$ & $\downarrow$ \\
\hline & \multirow[t]{3}{*}{$\mathrm{D}$} & 24 & - & $\uparrow$ & - & - & - & - & - \\
\hline & & 48 & - & - & $\downarrow$ & $\downarrow$ & - & - & - \\
\hline & & 72 & - & - & - & - & & - & - \\
\hline
\end{tabular}


the domesticated type (Fig. 2A). Furthermore, in present experiment, $\mathrm{q}_{\mathrm{P}}$ in the wild type was affected by the dose of UVB rather than that in the domesticated type. For example, after $24-48 \mathrm{~h}$ of UVB radiation, there was no significant change in $\mathrm{q}_{\mathrm{p}}$ in the wild type (Fig. $3 B, C$ ), but it was significantly reduced after 72 h (Fig. 3D). However, there was no significant difference in $\mathrm{q}_{\mathrm{P}}$ between $\mathrm{PAB}$ and PA in the domesticated type during the 24-72 $\mathrm{h}$ of UVB irradiation (Fig. $3 B-D$ ).

Consistent with the photosynthetic activity $\left(\mathrm{q}_{\mathrm{p}}\right)$ results, many other photosynthetic parameters of wild type decreased by UVB at $24 \mathrm{~h}\left(\mathrm{rETR}_{\max }\right.$ and $\left.\mathrm{E}_{\mathrm{k}}\right), 48 \mathrm{~h}\left(\mathrm{~F}_{\mathrm{v}} / \mathrm{F}_{\mathrm{m}}\right.$ and $\left.\Phi_{\mathrm{PSII}}\right)$, and $72 \mathrm{~h}\left(\Phi_{\mathrm{PSII}}, \mathrm{rETR}_{\max }\right.$, and $\left.\mathrm{E}_{\mathrm{k}}\right)$, respectively. However, minor photosynthetic parameters of domesticated type decreased at $48 \mathrm{~h}\left(\mathrm{rETR}_{\max }\right.$ and $\left.\mathrm{E}_{\mathrm{k}}\right)$, and $72 \mathrm{~h}(\alpha)$ (Table 1). Taken all the given data together, we can conclude that the wild type was more sensitive to UV stress, but it possesses more effective mechanisms to counteract it.

Yang et al. (2007) applied enhanced-UVB radiation on winter wheat (Triticum aestivum L.) seedlings at different growth temperature, and found that decreased $F_{v} / F_{m}$ and increased minimum fluorescence $\left(\mathrm{F}_{0}\right)$ were observed under high UVB $\left(0.119 \mathrm{~W} \mathrm{~m}^{-2}\right)$ at both temperatures $\left(25 / 20\right.$ or $\left.10 / 5^{\circ} \mathrm{C}\right)$ and low $\operatorname{UVB}\left(0.049 \mathrm{~W} \mathrm{~m}^{-2}\right)$ at $10 / 5^{\circ} \mathrm{C}$. They concluded that low temperature intensified UVBinduced photoinhibition and damage by weakening the antioxidant system (Yang et al. 2007). Huang et al. (2016) reported that moderate photoinhibition of PSII protects PSI from photodamage under chilling stress in tobacco leaves. In this study, the wild type was grown in an artificial climate room at $18^{\circ} \mathrm{C}(14 \mathrm{~h}) / 16^{\circ} \mathrm{C}(10 \mathrm{~h})$, while the domesticated type was grown in the chamber at $24^{\circ} \mathrm{C}$. Based on the literature above and our results, we suggest that low temperature is the reason why intensified UVB-induced photoinhibition (decreased $\mathrm{q}_{\mathrm{P}}, \mathrm{rETR}_{\max }$, $\mathrm{E}_{\mathrm{k}}, \mathrm{F}_{\mathrm{v}} / \mathrm{F}_{\mathrm{m}}$ ) was observed in the wild type rather than in the domesticated type. Furthermore, stomatal response to increased UV radiation can be a regulator of photosynthetic apparatus activity (Kosobryukhov et al. 2015). Majer and Hideg (2012) applied UVB of $0.84 \mathrm{~W} \mathrm{~m}^{-2}$ to supplement $50 \mu$ mol(photon) $\mathrm{m}^{-2} \mathrm{~s}^{-1}$ PAR daily, between 9-15 h. These conditions, much lower doses than those in our experiment $\left(8-\mathrm{h}\right.$ exposure to $2.3 \mathrm{~W} \mathrm{~m}^{-2}$ UVB for $3 \mathrm{~d}$ ), resulted in intense stomata closure and strong limitation of photosynthesis and decreased the photochemical yield $\left(\Phi_{\text {PSII }}\right.$ and $\left.\mathrm{F}_{\mathrm{v}} / \mathrm{F}_{\mathrm{m}}\right)$. Stomata in abaxial epidermal strips of Arabidopsis ecotype Landsberg erecta closed in response to increasing UVB rates, with maximal closure after $3-\mathrm{h}$ exposure to $2.89 \mathrm{~W} \mathrm{~m}^{-2}$ UVB (Tossi et al. 2014). Although the three experiments cannot be compared directly, due to differences in plant material (species, age), it is possible to hypothesize that stomata closure may occur in Rhododendron (especially in the wild type) because of much higher dose of UVB used in our study. Li et al. (2017) found that UVB-induced stomatal closure was promoted by mitogen-activated protein kinase phosphatases via modulating hydrogen peroxide-induced nitric oxide production in Arabidopsis guard cells.

UVB-induced limitation of photochemistry was not solely due to stomata closure which does not affect $F_{v} / F_{m}$, but internal PSII factors could also be involved (Majer and Hideg 2012). Although with the same PAR irradiances accompanying UVB $\left[50 \mu \mathrm{mol}\right.$ (photon) $\left.\mathrm{m}^{-2} \mathrm{~s}^{-1}\right]$, the two experiments cannot be compared directly due to UVB conditions [lower UVB used by Majer and Hideg (2012) and much higher UVB in our study]. However, both experiments showed the decrease of the photochemical yields indicated y $F_{v} / F_{m}$ and $\Phi_{\text {PSII. }}$ In accordance with this, a significant decrease in $\mathrm{F}_{\mathrm{v}} / \mathrm{F}_{\mathrm{m}}$ was observed in a 8-d study of grapevine (Vitis vinifera $\mathrm{L}$.) applying $0.081 \mathrm{~W} \mathrm{~m}^{-2} \mathrm{UVB}$ radiation with $165 \mu \mathrm{mol}\left(\right.$ photon) $\mathrm{m}^{-2} \mathrm{~s}^{-1}$ from 13:00 to 20:00 h (Schoedl et al. 2013), though two experiments cannot be compared directly, due to differences in plant material, PAR/UVB ratio [higher PAR/UVB ratio used by Schoedl et al. (2013) and much lower PAR/UVB ratio in our study].

Conclusion: From this study, we can conclude that the wild type was more sensitive to UV stress, but has more effective mechanisms to counteract it. The next challenge is a characterization of the differential proteins in two $R$. chrysanthum types after 48-h UV exposure, which could bring more information about the defense mechanism of the plant against UV radiation.

\section{References}

Albert K.R., Mikkelsen T.N., Ro-Poulsen H.: Effects of ambient versus reduced UV-B radiation on high arctic Salix arctica assessed by measurements and calculations of chlorophyll $a$ fluorescence parameters from fluorescence transients. Physiol. Plantarum 124: 208-226, 2005.

Albert K.R., Mikkelsen T.N., Ro-Poulsen H. et al.: Ambient UV-B radiation reduces PSII performance and net photosynthesis in high Arctic Salix arctica. - Environ. Exp. Bot. 72: 439-447, 2011.

Alonso R., Berli F.J., Bottini R., Piccoli P.: Acclimation mechanisms elicited by sprayed abscisic acid, solar UV-B and water deficit in leaf tissues of field-grown grapevines. - Plant Physiol. Bioch. 91: 56-60, 2015.

Beer S., Björk M., Gademann R., Ralph P.J.: Measurement of photosynthesis in seagrasses. - In: Short F.T., Coles R. (ed.): Global Seagrass Research Methods. Pp. 183-198. Elsevier Science, The Netherlands 2001.

Bernal M., Verdaguer D., Badosa J. et al.: Effects of enhanced UV radiation and water availability on performance, biomass production and photoprotective mechanisms of Laurus nobilis seedlings. - Environ. Exp. Bot. 109: 264-275, 2015.

Dehariya P., Kataria S., Guruprasad K.N., Pandey G.P.: Photosynthesis and yield in cotton (Gossypium hirsutum L.) var. Vikram after exclusion of ambient solar UV-B/A. - Acta Physiol. Plant. 34: 1133-1144, 2012.

Glenn D.M.: Effect of ultraviolet radiation environment on leaf quantum efficiencies and photosynthesis for tropical and temperate species. - Int. J. Fruit Sci. 18: 37-44, 2018.

Guidi L., Brunetti C., Fini A. et al.: UV radiation promotes flavonoid biosynthesis, while negatively affecting the biosynthesis and the de-epoxidation of xanthophylls: Consequence for photoprotection? - Environ. Exp. Bot. 127: 14-25, 2016.

Guruprasad K., Bhattacharjee S., Kataria S. et al.: Growth enhancement of soybean (Glycine max) upon exclusion of UV-B and UV-B/A components of solar radiation: characterization of photosynthetic parameters in leaves. - 
Photosynth. Res. 94: 299-306, 2007.

Henley W.J.: Measurement and interpretation of photosynthesis light-response curves in algae in the context of photoinhibition and diel changes. - J. Phycol. 29: 729-739, 1993.

Hideg E., Jansen M.A., Strid A.: UV-B exposure, ROS, and stress: inseparable companions or loosely linked associates? Trends Plant Sci. 18: 107-115, 2013.

Hou X.J., Hou H.J.M.: Roles of manganese in photosystem II dynamics to irradiations and temperatures. - Front. Biol. 8: 312-322, 2013

Huang W., Yang Y.-J., Hu H., Zhang S.-B.: Moderate photoinhibition of photosystem II protects photosystem I from photodamage at chilling stress in tobacco leaves. - Front. Plant Sci. 7: 182, 2016.

Kolb C.A., Kaser M.A.et al: Effects of natural intensities of visible and ultraviolet radiation on epidermal ultraviolet screening and photosynthesis in grape leaves. - Plant Physiol. 127: 863-875, 2001.

Li F.C., Wang J., Wu M.M. et al.: Mitogen-activated protein kinase phosphatases affect UV-B-induced stomatal closure via controlling NO in guard cells. - Plant Physiol. 173: 760-770, 2017.

Jansen M.A.K., Gaba V., Greenberg B.M.: Higher plants and UV-B radiation: balancing damage, repair and acclimation. Trends Plant Sci. 3: 131-135, 1998.

Jansen R.P., Dowzer C., Michaelis C. et al.: Mother cellspecific HO expression in budding yeast depends on the unconventional myosin and other cytoplasmic proteins. Cell 84: 687-697, 1996.

Joshi P., Gartia S., Pradhan M.K. et al.: Acclimation of clusterbean cotyledon to UV-B radiation in the presence of UV-A: partial restoration of photosynthetic energy balance and redox homeostasis. - Acta Physiol. Plant. 35: 2323-2328, 2013.

Kataria S., Jajoo A., Guruprasad K.N.: Impact of increasing ultraviolet-B (UV-B) radiation on photosynthetic processes. J. Photoch. Photobio. B 137: 55-66, 2014.

Klem K., Ač A., Holub P. et al.: Interactive effects of PAR and UV radiation on the physiology, morphology and leaf optical properties of two barley varieties. - Environ. Exp. Bot. 75: 52-64, 2012.

Klem K., Holub P., Štroch M. et al.: Ultraviolet and photosynthetically active radiation can both induce photoprotective capacity allowing barley to overcome high radiation stress. Plant Physiol. Bioch. 93: 74-83, 2015.

Kreslavski V.D., Lyubimov V.Y., Shabnova N.I. et al.: Heatinduced impairments and recovery of photosynthetic machinery in wheat seedlings. Role of light and prooxidant-antioxidant balance. - Physiol. Mol. Biol. Pla. 15: 115-122, 2009.

Kosobryukhov A.A., Lyubimov V.Y., Kreslavski V.D.: Adaptive mechanisms of photosynthetic apparatus to UV radiation. In: Tripathi B.N., Müller M. (ed.): Stress Responses in Plants. Pp. 59-78. Springer, Cham 2015.

Majer P., Hideg E.: Developmental stage is an important factor that determines the antioxidant responses of young and old grapevine leaves under UV irradiation in a green-house. Plant Physiol. Bioch. 50: 15-23, 2012.

Melis A., Nemson J.A., Harrison M.A.: Damage to functional components and partial degradation of PS II reaction center proteins upon chloroplast exposure to ultraviolet-B radiation.BBA-Bioenergetics 1100: 312-320, 1992.

Murali N.S., Teramura A.H.: Insensitivity of soybean photosynthesis to ultraviolet-B radiation under phosphorus deficiency. - J. Plant Nutr. 10: 501-515, 1987.

Neugart S., Schreiner M.: UVB and UVA as eustressors in horticultural and agricultural crops. - Sci. Hortic.-Amsterdam 234:
370-381, 2018.

Quesada A., Mouget J.-L., Vincent W.F.: Growth of Antarctic cyanobacteria under ultraviolet radiation: UVA counteracts UVB inhibition. - J. Phycol. 31: 242-248, 1995.

Ralph P.J., Gademann R.: Rapid light curves: a powerful tool to assess photosynthetic activity. - Aquat. Bot. 82: 222-237, 2005.

Rastogi R.P., Richa, Kumar A. et al.: Molecular mechanisms of ultraviolet radiation-induced DNA damage and repair. J. Nucleic Acid. 2010: 592980, 2010.

Reddy K.R., Kakani V.G., Zhao D. et al.: Interactive effects of ultraviolet-B radiation and temperature on cotton physiology, growth development and hyperspectral reflectance. Photochem. Photobiol. 79: 416-427, 2004.

Schoedl K., Schuhmacher R., Forneck A.: Correlating physiological parameters with biomarkers for UV-B stress indicators in leaves of grapevine cultivars Pinot noir and Riesling. J. Agr. Sci. 151: 189-200, 2013.

Schreiber U.: Pulse-amplitude (PAM) fluorometry and saturation pulse method: An overview. - In: Papageorgiou G.C., Govindjee (ed.): Chlorophyll Fluorescence: A Signature of Photosynthesis. Advances in Photosynthesis and Respiration. Pp. 279-319. Springer, Dordrecht 2004.

Skorrska E.: The effect of UV-B radiation on the chlorophyll fluorescence parameters of the husked and naked oat. - Acta Agrobot. 52: 149-152, 1999.

Sullivan J.H., Teramura A.H.: Field study of the interaction between solar ultraviolet-B radiation and drought on photosynthesis and growth in soybean. - Plant Physiol. 92: 141-146, 1990.

Štroch M., Materová Z., Vrábl D. et al.: Protective effect of UV-A radiation during acclimation of the photosynthetic apparatus to UV-B treatment. - Plant Physiol. Bioch. 96: 90-96, 2015.

Takeuchi Y., Ikeda S., Kasahara H.: Dependence on wavelength and temperature of growth inhibition induced by UV-B irradiation. - Plant Cell Physiol. 34: 913-917, 1993.

Tohidi-Moghadam H.R., Ghooshchi F., Jamshidpour F., Zahedi H.: Effect of UV radiation and elevated $\mathrm{CO}_{2}$ on physiological attributes of canola (Brassica napus L.) grown under water deficit stress. - Pol. J. Environ. Stud. 21: 1417-1427, 2012.

Tossi V., Lamattina L., Jenkins G.I., Cassia R.O.: Ultraviolet-Binduced stomatal closure in Arabidopsis is regulated by the UV RESISTANCE LOCUS8 photoreceptor in a nitric oxidedependent mechanism. - Plant Physiol. 164: 2220-2230, 2014.

Turcsányi E., Vass I.: Inhibition of photosynthetic electron transport by UV-A radiation targets the PSII complex. Photochem. Photobiol. 72: 513-520, 2000.

Turnbull T.L., Barlow A.M., Adams M.A.: Photosynthetic benefits of ultraviolet-A to Pimelea ligustrina, a woody shrub of sub-alpine Australia. - Oecologia 173: 375-385, 2013.

Tyystjarvi E.: Photoinhibition of photosystem II and photodamage of the oxygen evolving manganese cluster. - Coordin. Chem. Rev. 252: 361-376, 2008.

Vass I., Sass L., Spetea C. et al:: UV-B induced inhibition of photosystem II electron transport studied by EPR and chlorophyll fluorescence. Impairment of donor and acceptor side components. - Biochemistry 35: 8964-8973, 1996.

Vidović M., Morina F., Milić S. et al.: Ultraviolet-B component of sunlight stimulates photosynthesis and flavonoid accumulation in variegated Plectranthus coleoides leaves depending on background light. - Plant Cell Environ. 38: 968-979, 2015.

Visser A.J., Tosserams M., Groen M.W. et al.: The combined effects of $\mathrm{CO}_{2}$ concentration and solar UV-B radiation on faba bean grown in open-top chambers. - Plant Cell Environ. 20: 189-199, 1997. 
Wei Z., Cady C.W., Brudvig G.W., Hou H.J.M.: Photodamage of a $\mathrm{Mn}(\mathrm{III} / \mathrm{IV})$-oxo mixed-valence compound and photosystem II: Evidence that high-valent manganese species is responsible for UV-induced photodamage of oxygen-evolving complex in photosystem II. - J. Photoch. Photobio. B 104: 118-125, 2011.

Widel M., Krzywon A., Gajda K. et al.: Induction of bystander effects by UVA, UVB, and UVC radiation in human fibroblasts and the implication of reactive oxygen species. - Free Radical Bio. Med. 68: 278-287, 2014.

Yang Y.Q., Yao Y.: Photosynthetic responses to solar UV-A and UV-B radiation in low- and high-altitude populations of
Hippophae rhamnoides. - Photosynthetica 46: 307-311, 2008. Yang S.H., Wang L.J., Li S.H. et al.: The effects of UV-B radiation on photosynthesis in relation to Photosystem II photochemistry, thermal dissipation and antioxidant defenses in winter wheat (Triticum aestivum L.) seedlings at different growth temperatures. - Funct. Plant Biol. 34: 907-917, 2007.

Zhou X., Chen S., Wu H. et al.: Biochemical and proteomics analyses of antioxidant enzymes reveal the potential stress tolerance in Rhododendron chrysanthum Pall. - Biol. Direct 12: 10, 2017.

(C) The authors. This is an open access article distributed under the terms of the Creative Commons BY-NC-ND Licence. 